\title{
ANAESTHETIC CONSIDERATIONS IN BRONCHIAL ADENOMA
}

\author{
David M. Murphy, Charles H. Lockhart, and John D. Burrington
}

Bronchial Carcinom Tumor is an unusual tumor which has received considerable attention in the surgical literature; however, the anesthetic management of the tumor has not been previously discussed.

\section{Case Repont}

A 14-year-old white female was referred for evaluation with a five-week history of malaise, intermittent low-grade fever, and non-productive cough after failure to respond to antibiotic therapy. The only remarkable finding on physical examination was diminished breath sounds over the left posterior chest. Normal laboratory values included complete blood count, urinalysis, liver function tests, serum electrolytes and 24-hour urine 5-hydroxyindole acetic acid excretion. Chest roentgenograms demonstrated atelectasis of the left lower lobe and hyperlucency and hyperexpansion of the left upper lobe, particularly remarkable on expiratory films. An endobronchial mass completely occluding the left lower lobe bronchus and impinging upon the upper lobe bronchus was identified on tomograms. Pulmonary function studies showed increased residual volume and diminished vital capacity ( Table I). Nitrogen washout curves showed slow uneven elimination of nitrogen from the functional residual capacity (Figure 1). A diagnosis of bronchial adenoma was entertained and thoracotomy for resection of the portion of bronchus attached to tumour (sleeve resection) was planned.

One hour prior to induction of anaesthesia, morphine $6 \mathrm{mg}$, diazepam $10 \mathrm{mg}$, and atropine $0.4 \mathrm{mg}$ was given by intramuscular injection. An intra-arterial cannula for blood gas monitoring, placed after induction of anaesthesia, was used in addition to the usual monitoring devices. After thiopentone induction, spontaneous ventilation with halothane and oxygen was maintained during bronchoscopy. A mass with appearance compatible with bronchial adenoma was visualized in the left mainstem bronchus. It was not manipulated or biopsied. A \#7 Fogarty catheter was placed adjacent to the tumour under direct vision and the bronchoscope was removed. A $6.5 \mathrm{~mm}$ cuffed tracheal tube was positioned in the trachea above the carina and the patient was turned to the right lateral decubitus position. After thoracotomy the left upper lobe was seen to be markedly emphysematous and gas could not be expressed from it. The lower lobe was completely collapsed with extensive damage secondary to obstruction; therefore sleeve resection was not attempted. The Fogarty balloon was inflated slowly until it could be palpated by the operating surgeon. It was then positioned in the left mainstem bronchus just above the origin of the left upper lobe bronchus. The intermediate bronchus could then be opened and the

From: The Department of Anaesthesia, The Children's Hospital, Denver, Colorado. 
TABLE I

Pulmonary Function Studies Before and After Lower L.obectomy FOR BRONCHIAL ADENOMA

\begin{tabular}{lcll}
\hline \hline $\begin{array}{c}\text { Determinations } \\
\text { (liters) }\end{array}$ & $\begin{array}{c}\text { Predicted } \\
\text { normal }\end{array}$ & Pre-operative & Post-operative \\
\hline Forced vital capacity & 3.70 & $2.25(61 \%)$ & $3.11(84 \%)$ \\
Functional residual & 2.20 & $2.61(118 \%)$ & $2.38(108 \%)$ \\
capacity (FRC) & 1.00 & $1.97(197 \%)$ & $1.23(123 \%)$ \\
Residual volume & 4.70 & $4.22(89 \%)$ & $4.34(91 \%)$ \\
Total lung capacity & $21 \%$ & $47 \%$ & $28 \%$ \\
RV/TLC ratio (\%) & & & \\
\hline
\end{tabular}

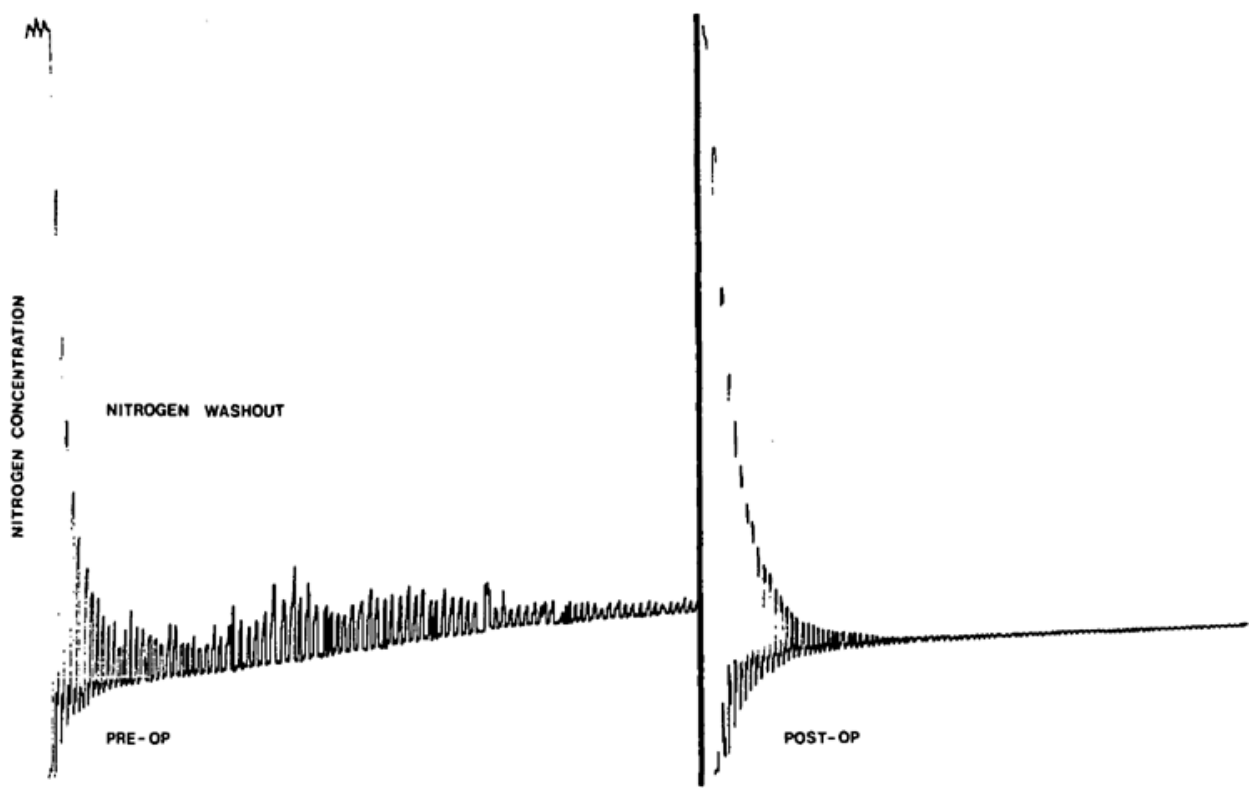

Figure 1. Nitrogen washout curves before and after removal of bronchial adenoma.

adenoma excised completely along with the damaged left lower lobe. The adenoma arose in the bronchus intermedius and extended from the orifice of the left upper lobe down into the segments of the lower lobe. The entire resection and plastic repair of the bronchus could be completed without significant gas leak since the Fogarty balloon completely blocked the left mainstem bronchus. Tightening a previously placed tourniquet about the left pulmonary artery prevented intrapulmonary shunting. The upper lobe ventilated normally after removal of the polypoid tumour which had caused a ball-valve type of obstruction. Arterial blood samples monitored frequently during anaesthesia had $\mathrm{P}_{\mathrm{O}_{2}}$ values ranging from 127 to $250 \mathrm{~mm} \mathrm{Hg}$. The post-operative course was unremarkable. Pathological diagnosis was carcinoid type of bronchial adenoma.

\section{Discussion}

Bronchial adenoma is a clinical classification which includes cylindroma, bronchial carcinoid tumour, and mucoepidermoid tumour. These three tumours 
are pathologically dissimilar and share only a low-grade malignant potential and a tendency to occur within the bronchi. They constitute 1 to 6 per cent of primary bronchial tumours in adults. ${ }^{1,2}$ Because of the rarity of bronchial tumours in children, bronchial adenoma probably comprises more than half of the primary bronchial tumours in the paediatric population. ${ }^{3}$ Bronchial carcinoid tumour constitutes $80-90$ per cent of bronchial adenomas; ${ }^{4,5}$ this tumour is thought to arise from argentaffin (Kultchitsky) cells in the bronchial mucosa. ${ }^{8}$

Patients usually present with signs and symptoms of bronchial obstruction, such as cough, recurrent pneumonia, atelectasis, wheezing, or haemoptysis. Carcinoid syndrome is seen in 2 per cent to 7 per cent of adults; ${ }^{7}$ we have not found reports of symptomatic carcinoid syndrome due to this lesion in the paediatric age group although a child has been described with metastatic bronchial carcinoid tumour, elevated plasma serotonin levels and increased urinary 5-hydroxyindole acetic acid excretion. ${ }^{8}$ Cushing's syndrome has been described in an 18-year-old male with bronchial carcinoid tumour. ${ }^{9}$

The differential diagnosis in the paediatric age group will include aspirated foreign body, granuloma, cystic fibrosis, chronic bronchitis, bronchiectasis and other tumours; ${ }^{5}$ conversely bronchial adenoma should be considered in the differential diagnosis of these conditions.

Pulmonary function studies (Table I) in this case reflect a ball-valve type of obstruction manifested by increased residual volume due to air trapping in the left upper lobe and diminished vital capacity due to obstruction of the upper lobe during expiration and to loss of the lower lobe volume.

The nature of the tumour and of the surgical procedure poses several problems for the anaesthetist. Because the lesion is friable and vascular, surgical manipulation can cause fragmentation or massive bleeding into the bronchus. Thus airway obstruction or haemorrhage may occur precipitously. Two deaths due to haemorrhage following biopsy have been reported; ${ }^{4}$ for this reason biopsy is not recommended, particularly in patients with a history of haemoptysis.

With infected and atelectatic parenchymal tissue behind the obstruction, copious volumes of infected secretions may become entrapped in the distal airway. Position change or manipulation may free these secretions into the proximal airway and cause obstruction and contamination of normal lung.

Although the malignant potential is recognized, sleeve resection of the tumour and the involved portion of the bronchus appears to provide the best chance of cure while preserving a maximum of lung parenchyma. However, this procedure may require a prolonged period when the bronchus is left open, causing a potential large air leak which may make ventilation difficult or impossible.

Protection for the dependent lung and elimination of air leaks can be accomplished by several methods. A double-lumen tracheal tube such as the Carlen's catheter has been used but may not be feasible in the paediatric patient due to size limitations. One-lung ventilation can be achieved by bronchial intubation; however, this must be done blindly at a critical operative stage, and there is a possibility of failure of cannulation of the desired bronchus. Various bronchial blockers are available. We chose the Fogarty catheter as described by Hogg and Lorhan ${ }^{10}$ with placement under direct vision rather than blindly. This can be used in paediatric 
patients as young as one year of age. Its small size causes little compromise of airway size. Because it is easily inflated and deflated it allows minimum one-lung ventilation time as recommended by Khanam and Branthwaite ${ }^{11}$ without the problems inherent in manipulation of a tracheal tube in a patient in the lateral position.

Anaesthetic implications of the pathophysiology and pharmacology of serotonin and other vasoactive amines involved in malignant carcinoid syndrome have been reviewed by Lippmann and Cleveland, ${ }^{12}$ and by Stone and Donnelly. ${ }^{13}$ While malignant carcinoid syndrome has not been reported in association with bronchial carcinoid tumours in children, these articles can be consulted before managing a patient with the disease.

\section{SUMMARY}

The patient with bronchial adenoma can present a puzzling diagnostic dilemma as well as challenging problems in anaesthetic management. Several aspects are reviewed in this report. Diagnostically these include chest roentgenographic findings and unique pulmonary function tests. Problems in anaesthetic management include possible development of acute carcinoid syndrome, as this tumour is usually of the carcinoid variety. In addition, the tumour may act as a ball valve, causing uneven ventilation of affected lung with expiratory air trapping. Several factors may necessitate prolonged bronchial blockage during anaesthesia. These include a friable mass which may bleed profusely upon manipulation, infected and atelectatic parenchymal tissue beyond the obstruction, copious volumes of purulent secretions, and one lung ventilation during resection.

\section{RÉSUMÉ}

Le diagnostic différentiel d'adénome bronchique peut présenter des difficultés particulières.

Ce travail discute entre autres de la contribution de la radiologie et des tests de fonction respiratoire au diagnostic.

Au moment de l'intervention, ces malades présentent un déf particulier à l'anesthésiste.

On doit garder à l'esprit la possibilité d'un syndrome carcinoïde aigu, la plupart de ces tumeurs étant de la variété carcinoïde.

La tumeur peut se comporter comme une valve unidirectionnelle avec séquestration d'air en aval et distribution inégale de la ventilation.

Plusieurs facteurs peuvent requérir la présence d'un bloqueur bronchique en per-opératoire à savoir un tissu tumoral friable susceptible de saigner abondamment au cours des manipulations, la présence de parenchyme infecté et atélectasique, la présence de sécrétions purulentes abondantes et la nécessité de ventiler un seul poumon.

\section{REFERENCES}

1. Zellos, S. Bronchial adenoma. Thorax, 17: 6I-68 (1962).

2. Ward, D.E., Jr., Bradshaw, H.H., \& Prince, T.C. Bronchial adenoma in children. J. Thorac. Surg. 27: 295-299 (1954). 
3. DeParedes, C.G., Pierce, W.S., Groff, D.B., \& Waldhausen, J.A. Bronchogenic tumors in children. Arch. Surg. 100: 574-576 (1970).

4. Wilkens, E.W., Jr., Darling, R.C., Soutter, L., \& Sniffen, R.C. A continuing clinical survey of adenomas of the trachea and bronchus in a general hospital. J. Thorac. Cardiovasc. Surg. 46: 279-289 (1963).

5. Verska, J.J. \& Connolly, J.E. Bronchial adenomas in children. J. Thorac. Cardiovasc. Surg. 55: 411-417 (1968).

6. Bensch, K.G., Corhin, B., Pariente, R., \& Spencer, H. Oat-cell carcinoma of the lung its origin and relationship to bronchial carcinoid. Cancer, 22: 1163-1172 (1968).

7. Ricci, C., Patrassi, N., Massa, N., Mineo, C., \& Benedetti-Valentine, F., Jr. Carcinoid syndrome in bronchial adenoma. Am. J. Surg. 14: 453-463 (1972).

8. Turnbull, A.D., Huvos, A.G., Goonner, J.T., \& Beattie, E.J., Jr. The malignant potential of bronchial adenoma. Ann. Thorac. Surg. 14: 453-463 (1972).

9. Olurin, E.O., Sofowora, E.O., Afonja, A.O., Kolawole, T.M., \& Junaid, T.A. Cushing's syndrome and bronchial carcinoid tumor. Cancer. 31: 1514-1519 (1973).

10. Hogg, C.E. \& LoRHan, P.H. Pediatric bronchial blocking. Anesthesiology 33: 560-562 (1970).

11. Khanam, T. \& Branthwatte, M.A. Arterial oxygenation during one-lung anesthesia (2). Anesthesia 28: 280-290 (1973).

12. LippmanN, M. \& Cleveland, R.J. Anesthetic management of a carcinoid patient undergoing tricuspid valve replacement. Anesth. Anal. 52: 768-771 (1973).

13. Stone, H.H. \& Donnelly, C.C. The anesthetic significance of serotonin secreting carcinoid tumors. Anesthesiology 21: 203-212 (1960). 